\title{
Trabalho e educação: a produção do conhecimento
}

\author{
Work and education: the production of knowledge \\ Trabajoy educación: la producción de conocimiento
}

Recebido: 17/08/2021 | Revisado: 27/08/2021 | Aceito: 02/10/2021 | Publicado: 04/10/2021

Raimundo Jackson Nogueira da Silva ${ }^{1}$

ORCID: https://orcid.org/0000-0001-9534-6431 Instituto Federal de Educação, Ciência e Tecnologia do Ceará, Brasil E-mail: jacksoneafi13@gmail.com

Emanoel Rodrigues Almeida

ORCID: https://orcid.org/0000-0001-9787-0851 Instituto Federal de Educação, Ciência e Tecnologia do Ceará, Brasil E-mail: emanoel.almeida@ifce.edu.br

Emanoelyna Gonçalves Jucá ${ }^{1}$

ORCID: https://orcid.org/0000-0002-9616-1954 Instituto Federal de Educação, Ciência e Tecnologia do Ceará, Brasil E-mail: emanoelynagj@gmail.com

\begin{abstract}
Resumo
O objetivo geral desta pesquisa é possibilitar uma experiência de investigação da relação entre trabalho e educação. Os objetivos específicos consistem em: 1) Compreender a categoria trabalho na perspectiva ontológica do ser social; 2) Debater sobre a relação do trabalho e a reprodução do ser social como categoria necessária ao ser humano e o processo sócio histórico do desenvolvimento humano. A metodologia consiste no método ontológico de caráter qualitativo, sendo bibliográfica baseando principalmente nos autores Tonet (2016) e Lessa (2016). Conclui-se que o trabalho é a categoria fundante do ser social, e que está intimamente ligado ao complexo da educação, responsável pelo acúmulo do conhecimento e avanço das relações sociais. Apesar do conhecimento possuir um papel social, ainda não atingiu o ápice da consciência humana, sendo possível somente com o fim das classes sociais.
\end{abstract}

Palavras-chave: Ontologia; Educação; Conhecimento; Consciência.

\begin{abstract}
The general objective of this research is to enable an investigation experience of the relationship between work and education. The specific objectives consist of: 1) Understanding the category of work from the ontological perspective of the social being; 2) Debate about the relationship between work and the reproduction of the social being as a necessary category for the human being and the socio-historical process of human development. The methodology consists of the ontological method of qualitative character, being bibliographical based mainly on the authors Tonet (2016) and Lessa (2016). It is concluded that work is the founding category of the social being, and that it is closely linked to the education complex, responsible for the accumulation of knowledge and the advancement of social relations. Although knowledge has a social role, it has not yet reached the peak of human consciousness, being possible only with the end of social classes.
\end{abstract}

Keywords: Ontology; Education; Knowledge; Conscience.

\section{Resumen}

El objetivo general de esta investigación es posibilitar una experiencia investigadora de la relación entre trabajo y educación. Los objetivos específicos consisten en: 1) Comprender la categoría de trabajo desde la perspectiva ontológica del ser social; 2) Debate sobre la relación entre el trabajo y la reproducción del ser social como categoría necesaria para el ser humano y el proceso sociohistórico del desarrollo humano. La metodología consiste en el método ontológico de carácter cualitativo, siendo bibliográfico basado principalmente en los autores Tonet (2016) y Lessa (2016). Se concluye que el trabajo es la categoría fundacional del ser social, y que está íntimamente ligado al complejo educativo, responsable de la acumulación de conocimientos y el avance de las relaciones sociales. Si bien el conocimiento tiene un rol social, aún no ha alcanzado la cúspide de la conciencia humana, siendo posible solo con el fin de las clases sociales.

Palabras clave: Ontología; Educación; Conocimiento; Conciencia.

1 Mestrando(a) em Ensino e Formação Docente (UNILAB-IFCE- Instituto Federal de Educação, Ciência e Tecnologia do Ceará, Brasil. 


\section{Introdução}

Para compreender as transformações na sociedade em suas amplas dimensões, é necessário conhecer o ser e sua intervenção no mundo, partindo do pressuposto de que o que nos diferencia dos seres orgânicos e inorgânicos é a nossa capacidade de produzir o novo, através do trabalho.

Lessa (2016), aponta que Lukács definiu que existem três esferas ontológicas diferentes: o inorgânico, cuja essência é tornar-se continuamente mineral; o biológico, cuja essência é substituir a reprodução da vida, por meio da transformação contínua do mundo; e por fim, o ser social cuja a existência é caracterizada pela produção contínua de novos produtos.

Apesar de que somente o ser social é capaz de produzir novos produtos, não podemos limitar a importância das outras esferas, pois sem elas, não haveria vida humana. Embora essas três esferas ontológicas sejam diferentes, elas estão ligadas, pois, sem o reino inorgânico não há vida, e sem vida não há ser social. Isso porque existe um procedimento evolutivo que conecta três esferas: surgiu da vida inorgânica e dela um ser social. Santos (2018) aponta que à medida que o indivíduo caminha na direção do social, distancia-se da esfera natural, no entanto, sem jamais se desprender dela. O que ocorre é apenas um afastamento das barreiras naturais, nunca um rompimento absoluto com as demais esferas do ser.

Lukács ressalta em suas obras que o homem é o motor da sociedade, fonte geradora das transformações e do conhecimento, partindo da sua consciência, que é a chave mestra para executar ou colocar em prática a subjetividade, que logo se transformará/construirá algo, o que podemos denominar de objeto. Tonet (2016), destaca que o trabalho é o agente preposto das relações sociais, ele que articula as transformações no mundo, visto que ao transformar a natureza, os homens também se transformam a si mesmos. Evidentemente, o mundo não é constituído apenas pelo trabalho, mas também por muitas outras dimensões. Todas elas, porém, relativa - tem sua raiz no trabalho. Engels (2012) explica que a ação do homem sobre o mundo, no sentido de dominar a natureza para satisfazer suas necessidades primeiras, através do trabalho, foi responsável pela constituição de características tipicamente humanas. Já Fonte (2018) destaca que o trabalho em discussão não é o emprego, mas sim, no sentindo ontológico, o ato através do qual o ser social se constituiu e vem se desenvolvendo ao longo da história.

Resgatando o processo inicial das relações sociais, considerando os seres orgânicos, inorgânicos e social, o objetivo geral desse texto é possibilitar uma experiência de investigação da relação entre trabalho e educação na perspectiva ontológica. Os objetivos específicos consistem em: 1) compreender a categoria trabalho na perspectiva ontológica do ser social; 2) debater sobre a relação do trabalho e a reprodução do ser social como categoria necessária ao ser humano e ao processo sócio histórico do desenvolvimento humano.

\section{Metodologia}

O presente estudo apoia-se no método ontológico, parte do pressuposto que a objetividade determina o conhecimento. Conforme Tonet:

[...] o ponto de vista ontológico implica a subordinação do sujeito ao objeto, vale dizer que, no processo de conhecimento, o elemento central é o objeto. Neste sentido, não cabe ao sujeito criar - teoricamente - o objeto, mas traduzir, sob a forma de conceitos, a realidade do próprio objeto (TONET, 2016, p. 16).

Do ponto de vista dos objetivos é uma pesquisa exploratória, "Pesquisas exploratórias são desenvolvidas com o objetivo de proporcionar visão geral, de tipo aproximativo, acerca de determinado fato [...]” (Gil, 2008), de caráter qualitativo, pois procura compreender como a realidade social é construída: “a pesquisa qualitativa responde a questões muito particulares. Ela se ocupa, nas Ciências Sociais, com um nível de realidade que não pode ou não deveria ser quantificado. Isto é, ela 
trabalha com o universo dos significados, dos motivos, das aspirações, das crenças, dos valores e das atitudes. (Mynayo,2009, p.21). Através deste estudo procuraremos entender como a relação do trabalho e educação são construídas socialmente.

Trata-se de uma pesquisa bibliográfica, já que ela estará fundamentada, essencialmente, na consulta a livros, revistas, e artigos, etc. Esse trabalho estará assentado no materialismo histórico e dialético e contará com a contribuição de teóricos como: Tonet (2016), Lessa (2016), entre outros.

O estudo, buscará compreender a importância da categoria trabalho e educação na perspectiva ontológica do ser social. Para percorrer o caminho metodológico viável, o estudo se concentrará na compreensão inicial dos seres orgânico, inorgânico e social, posteriormente fazendo recorte do trabalho como protoforma social e por fim, a relação da categoria educação e trabalho no construto social e do conhecimento, destacando as épocas greco-medieval e moderna.

\section{Resultados e Discussão}

\subsection{Trabalho: mediação e protoforma do ser social}

Para tratarmos da atividade trabalho como mediação e protoforma do ser social é necessário compreendermos as relações entre as esferas ontológicas do ser: orgânico, inorgânico e social.

O ser inorgânico não possui vida, sendo apenas um movimento de convergência para transformação de outro elemento, como exemplo: a pedra que após anos/séculos se transforma em terra, causada por diversos efeitos que não cabe a este estudo. O processo evolutivo do ser inorgânico, sua história, tem como característica ontológica decisiva a transformação, mediante processos físicos e químicos, em algo distinto de si mesmo, dos elementos que o conformam. Transformar-se em outro é a qualidade essencial dessa forma de organização da matéria Rolim (2017).

Já a esfera orgânica, consiste na reprodução do mesmo, como exemplo a mangueira, que foi citada por Lessa (2016). Essas duas esferas são totalmente diferentes, em que uma não pode originar a outra, mas, que ambas se complementam. Essa distinção impede que uma esfera derive diretamente de outra esfera. Rolim (2017), destaca que no ser orgânico a peculiaridade de seu desenvolvimento, a essência dessa nova forma de organização da matéria, é a reprodução de seres vivos com a mesma constituição biológica. Em outras palavras, é a possibilidade da reprodução do mesmo.

Os seres orgânicos só podem se tornar inorgânicos com a morte. Este é o momento em que a vida é destruída. Por outro lado, as substâncias inorgânicas que compõem a matéria orgânica devem obedecer às leis da biologia, ou seja, estão associadas à reprodução biológica. O movimento objetivo de substâncias inorgânicas incorporadas em processos biológicos resulta em apenas se tornar um outro tipo de natureza processual inorgânica, e a natureza processual inorgânica é determinada principalmente pela substituição da reprodução biológica. Tornar-se outra substância inorgânica é apenas parte desses processos biológicos globais (não importantes). Importante destacar que entre o reino inorgânico e a vida, há uma ruptura no modo de existência e há uma ruptura no corpo.

O ser social se diferencia das demais esferas pela sua consciência, capacidade de pensar, articular ideais, projetar e executar algo. Diferencia-se ontologicamente através do trabalho. Essas transformações geram uma cadeia de ações e consequências, na qual Lukács definiu de casualidade, ou seja, que as nossas ações conscientes, podem e afetam outras ações. No modo natural, orgânico e inorgânico, teremos como exemplo a reprodução dos elementos ou as transformações destes. Já no mundo social, estaremos lidando com as relações mediadoras do cotidiano, onde na qual, o conhecimento acumulado, seja de pelo indivíduo ou de geração para geração, promove sempre mudanças sociais. Bizerra (2015), destaca que os processos sociais são orientados pela ação consciente dos homens, pela ação transformadora destes ao encontrarem cada vez menos "prontas" as condições para sua reprodução, produzindo-as, sempre de maneira nova, pelo trabalho. Esse processo de relações podemos destacar como um conjunto de partes para assegurar sua sobrevivência, que é partida originária do trabalho, 
considerada por Tonet (2016, p.26) como categoria matrizadora do mundo, pois ao produzir os bens materiais necessários à existência humana, dá origem ao mundo social. Nesse sentido, Tonet (2011) afirma que:

Da constatação de que o trabalho é o ato ontológico-primário do ser social segue-se, como consequência lógica, que este é radicalmente histórico e radicalmente social. Radicalmente histórico porque tudo o que compõe o ser social, inclusive a essência humana, é criado ao longo desse processo. Vale dizer, não há nenhuma parte que integre o ser social que seja de origem divina ou puramente natural. Radicalmente social porque tudo o que compõe o ser social é resultado da interatividade humana. Tudo é resultado da atividade social dos homens.

Lima (2011), os complexos sociais só alcançam autonomia num contexto já crescentemente sociabilizado pelo desenvolvimento do trabalho. Mas tal autonomia não pode se configurar de forma absoluta. Ela é sempre relativa, justamente por conta da dependência ontológica que está na base da sua relação com o trabalho. Para compreensão da distinção e articulação das três esferas ontológicas, somente é possível quando consideramos o que Lukács depois de Marx chamou de momento predominante, podemos incluir corretamente a distinção e expressão simultâneas dos três campos ontológicos: inorgânico, orgânico e social. Nesse processo, um desses elementos deve predominar sobre o outro, a fim de que possa permitir a dinâmica da evolução. Lessa (2016, p.22) ressaltou que:

Em outras palavras as contradições, por si mesmas, resultariam em um equilíbrio dinâmico estacionário do processo, inviabilizando toda evolução. “/.../ a simples interação conduz a um arranjo estacionário, definitivamente estático; se queremos dar uma expressão conceitual à dinâmica viva do ser, ao seu desenvolvimento, devemos elucidar qual seria, na interação da qual se trata, o momento predominante."

Na análise ontológica de Lukács, "a transição de um domínio de existência para outro" mostra claramente a função do momento dominante. A forma geral desta passagem é chamada de salto ontológico. Para Lukács, "todo salto implica uma mudança qualitativa e estrutural do ser, na qual a fase inicial contém certamente em si determinadas premissas e possibilidades das fases sucessivas e superiores, mas estas não podem se desenvolver daquelas a partir de uma simples e retilínea continuidade. A essência do salto é constituída por essa ruptura com a continuidade normal do desenvolvimento e não pelo nascimento repentino ou gradual, ao longo do tempo, da nova forma de ser” (LUKÁCS, 2013, p. 17-8).

Lessa (2016), destaca que:

O salto corresponde ao momento negativo de ruptura, negação, da esfera ontológica anterior; é este momento negativo que compõe a essência do salto. Todavia, a explicitação categorial do novo ser não se esgota no salto. Requer um longo e contraditório processo de construção das novas categorias, da nova legalidade e das novas relações que caracterizam a esfera nascente. Esse longo processo, cuja positividade (afirmação do novo ser) contrasta com a negatividade do salto, é o processo de desenvolvimento do novo ser.

A nova existência surge dos aspectos positivos e negativos do salto comparação de ontologias. Não há vida nova sem salto. Salto semelhante ocorre no processo de vida para a sociedade. Lukács acredita que o trabalho é a chave do principal salto da vida no mundo humano. Em outras palavras, o trabalho leva à interação social das pessoas, por meio da qual os humanos podem interagir, atender e criar suas próprias necessidades. Nesse processo, as pessoas criaram a si mesmas (modos de vida) e, assim, surgiu a existência social. Marx (2001):

O trabalho é um processo de que participa o homem e a natureza, processo em que o ser humano, com sua própria ação, impulsiona, regula e controla seu intercâmbio material com a natureza... Põe em movimento as forças naturais de seu corpo - braços e pernas, cabeça e mãos -, a fim de apropriar-se dos recursos da natureza, imprimindo-lhes forma útil à vida humana. Atuando assim sobre a natureza externa e modificando-a, ao mesmo tempo modifica sua própria natureza (MARX, 2001, p. 211). 
Sociedades mais complexas exigem indivíduos mais complexos, indivíduos mais complexos exigem sociedades mais complexas Tonet (2011). Nesse ambiente, quanto mais complexo tornou-se o ser humano, mais distante ele se distanciou da natureza, de sua dependência, passando a tornar um ser social, pautável na sociabilidade, surgindo então os complexos sociais, como o direito, a educação, a economia e entre outros. Esse afastamento também é sentido nas próprias relações, que sai da relação comunitária e entra o singular, individual, sustentado pelo que os teóricos chamam de privado. Nessa relação, está claramente a divisão do trabalho e o início das suas especializações, pois são esses conflitos que diferenciam o ser social do ser orgânico, que conforme Tonet (2013), é composto por dois momentos, de igual estatuto ontológico: o momento da singularidade e o momento da universalidade, o indivíduo e o gênero. E esses dois momentos se constituem mutuamente. Tonet (2013), deixa claro esse processo de transformação, onde afirma que:

A transformação do ser humano singular em indivíduo levou milhares de anos. Ele implica a apropriação, por parte do indivíduo, das objetivações que foram se tornando patrimônio do gênero humano, tornando-as suas de maneira específica. Este processo de individuação, porém, não foi linear. Implicou profundas transformações e rupturas. Grosso modo, poderíamos dizer que ele teve dois grandes momentos. O primeiro, que vai desde os primórdios da humanidade até o final do período medieval. Durante esse período, na relação entre ser humano singular e comunidade, a predominância era da comunidade. De um início inteiramente gregário, os homens foram passando a um estado onde as relações entre estas duas dimensões se tornaram cada vez mais flexíveis e diferenciadas.

A transição de um nível de existência para outro é um processo lento. Em suma, representa uma mudança qualitativa nos aspectos estruturais da existência. Neste momento importante entre a natureza e o mundo, a vida humana natural é estabelecida no trabalho. Para Lukács, a categoria trabalho é a principal forma de ação humana. Isso não significa que todo comportamento humano é trabalho, mas sem trabalho não haveria atividades sociais humanas de alguma forma.

Como categoria fundadora da existência social, o trabalho tem prioridade ontológica em relação a outras categorias e complexos sociais, e estes só podem ser produzidos no contexto de uma socialidade já constituída. Em seu cerne, a sociedade como um todo mostra o tempo dominante. O complexo social só pode conquistar autonomia em um ambiente cada vez mais socializado com o desenvolvimento do trabalho.

Almeida (2021), o trabalho é uma continuação dos elementos ontológicos do ser orgânico e ao mesmo tempo uma descontinuidade na medida em que produz um novo ser ontologicamente diferente do ser orgânico. Esta especificidade do trabalho lhe assegura acento privilegiado na constituição do ser social

Mas essa autonomia não pode ser definida de forma absoluta. É sempre relativo, justamente por sua dependência ontológica da relação de trabalho. A autonomia estabelecida nestes complexos decorre do facto de, para desempenharem funções específicas e essencialmente distintas da comunicação entre o homem e a natureza, possuírem características específicas que os distinguem do trabalho.

Por mais que seja individualizado ou coletivo, o trabalho e sua natureza sempre será um ato social, pois há nele um processo de humanização.

Marx, reforçou essa ideia quando em suas obras pontuou:

Mesmo quando eu sozinho desenvolvo uma atividade científica, etc. uma atividade que raramente posso levar a cabo em direta associação com outros, sou social, porque é enquanto homem que realizou tal atividade. Não é só o material da minha atividade - como também a própria linguagem que o pensador emprega - que me foi dado como produto social. A minha própria existência é atividade social (1989, p. 195).

O trabalho é a categoria fundante do ser social, responsável pela sua humanização, pelo aperfeiçoamento e habilidades de domínios da natureza, pela criação dos objetos e principalmente, pela autonomia ou domínio do homem a si mesmo. Todos os demais complexos existentes, estão ligados ao trabalho, pois sem a elevação dessa categoria, não seria possível o 
surgimento ou manutenção de outras atividades. Lessa (2012), coloca que o trabalho é a necessidade mais predominante dos homens, exercendo decisiva razão de ser imanente a toda e qualquer organização social.

A relação do homem com a natureza é mediada pelo trabalho, que é o fundamento ontológico da busca por uma vida plena de sentido. Essas considerações permitem perceber como o trabalho impulsiona o homem em cada ato, nas vivências e própria existência que colaboram para o surgimento de outros complexos sociais, como religião, filosofia, arte, ética, entre outros, para atender as necessidades impostas pelo processo de sociabilização.

\subsection{Educação e a reprodução do ser social}

O surgimento de diferentes complexos como a educação, a linguagem, se dá pela sociabilidade do ser social, pela necessidade de garantir e promover o desenvolvimento e a reprodução social, estimuladas por interesses individuais e coletivos. "[...] o homem transforma a natureza em objetos que possam atender às suas necessidades fundamentais $[\ldots]$ " (Nascimento, 2016). Esse momento de avanço nos complexos é determinante para caracterizar o salto ontológico, ou seja, momento de transformação.

Destaca-se que apesar de existir diversos complexos e o surgimento de tantos outros, não se pode negar que o trabalho é a categoria fundante do ser social, e que direta ou indiretamente, os complexos acabam tendo ligações a ele. Lukács (1979), enfatizou claramente a importância do trabalho como categoria fundante do ser social, pois para ele, em primeiro lugar, do ponto de vista genérico, o trabalho é o ponto de partida da humanização do ser humano e do aprimoramento contínuo de seus talentos e, nesse processo, as pessoas não podem deixar de dominar a si mesmas. Além disso, esse trabalho foi o único escopo desse desenvolvimento por muito tempo. Todas as outras formas de atividades humanas relacionadas a outros valores só podem se manifestar como autonomia depois que o trabalho atingiu um nível relativamente alto.

O complexo da educação é baseado no trabalho, pois existe entre eles a relação entre identidade, identidade e não identidade. O fato de o trabalho ter se tornado modelo para todas as práticas sociais, inclusive a educação, confirma essa identidade. Portanto, como o trabalho, a educação se caracteriza pela objetivação da posição teleológica e do movimento de causalidade, sendo realizada por meio da relação de ambas.

Maceno (2017), a educação é um complexo indissociável da socialidade; como tal, aparece quando esta surge. Sua origem, e, por consequência, sua função social remetem ao surgimento dessa esfera do ser, mais complexa, que é o ser social. Nenhuma apreensão do complexo educativo é possível sem partir da origem do ser social.

De acordo com isso, a forma original do trabalho "sofreu uma mudança substancial quando o ponto de vista teleológico não é mais usado exclusivamente para transformar objetos naturais e usar processos naturais, mas para induzir outros a assumir certas posições." Nesse sentido, a não identidade se reflete no fato de que a teleologia principal foi posta em funcionamento, realizando a troca entre o homem e a natureza, e pretendendo transformar objetos naturais em valores de uso, e na educação, a teleologia secundária visa influenciar os outros indivíduos que ocupam certas posições. É essa diferença essencial que está na base do conceito educacional de Lukács. Na perspectiva da ontologia, a educação não é trabalho, é práxis, a educação é eficaz e sua função a conecta com a reprodução social.

Para compreendermos essa afirmação, é necessário entendermos que a sociedade é composta por dois polos distintos, sendo o polo da singularidade e o polo da universalidade. Outro fator importante, é que o indivíduo não nasce indivíduo, mas se constitui indivíduo por meio das relações sociais, culturais e econômicas impostas a ele. O polo da universalidade se constitui ao efeito geral, genérico da formação humana e da sociedade, o que chamamos de polo universal. Já o polo singular, se refere a formação do ser social, do indivíduo, que são capturas do patrimônio universal, tornando-o indivíduo humano.

Ao contrário dos animais, nós, humanos, não nascemos com a determinação de nos envolver nas atividades necessárias à nossa sobrevivência. Precisamos aprender o que vamos fazer. É exatamente porque trabalho implica teleologia, 
ou seja, a existência de atividades intencionais anteriores e alternativas, não são biologicamente predeterminados. Precisa assumi-lo conscientemente. Portanto, é necessária a educação, ou seja, o processo de aquisição de conhecimentos, habilidades, comportamentos, valores, etc., que capacite os indivíduos a participarem conscientemente da vida social.

Com a aquisição desses conhecimentos, habilidades e outras funções, Lukács apud Tonet (2011), enfatiza que:

Toda sociedade demanda dos seus próprios membros uma dada massa de conhecimentos, habilidades, modos de comportamento, etc.; contudo, duração, etc. da educação em sentido estrito são consequências das necessidades sociais surgidas (1981, p. 153).

A educação é conservadora, pois consegue manter vivo o patrimônio da humanidade, ao mesmo tempo, permite a sociabilidade, a construção e o repasse desse conhecimento de geração a geração. O mundo tecnológico atual, só foi permitido devido ao acúmulo do conhecimento, das experiências e descobertas anteriores, que pouco ou muito, permite a evolução tecnológica cada vez mais acelerado.

O processo educativo escolar é reduzido ao exercício da cidadania e à qualificação imediata para inserção no mercado, negligenciando a formação humana, alinhado à perspectiva neoliberal, concebendo a educação escolar como 'promessa' para as classes pobres elevarem-se tanto no âmbito econômico quanto no social e cultural, ocultando a contradição fundamental entre capital e trabalho (ALVES, 2002).

Ao contrário da categoria do trabalho, como citamos anteriormente, a educação é práxis, pois no trabalho, conseguimos projetar teleologicamente e executar. Já a educação, é uma relação de teoria e prática, sendo que seu sentido não é determinado por ela. Tonet (2011), destaca que:

Nesses vários níveis se decide a sua forma concreta, mas não o seu sentido mais profundo. Este é definido pelas necessidades mais gerais da reprodução do ser social. Ora, como o trabalho é o fundamento ontológico do ser social, é óbvio que, em cada momento e lugar históricos, uma determinada forma de trabalho será a base de uma determinada forma de sociabilidade e, portanto, de uma certa forma concreta de educação (2011, p.7).

Nesse sentido, vamos ter a educação nas três vertentes: dependência ontológica, autonomia relativa e determinação recíproca. No que consiste a dependência ontológica, a educação está condicionada na forma como o homem se relaciona com a natureza, isso vai depender das transformações, o que delimitam o seu grau de articulação de dependência. Em cada momento histórico, essa relação é diferente. Já na vertente da autonomia, vai depender da forma como ela se constitui, da forma como ela se organiza, se categorizando como função ou esfera. Na determinação recíproca, está na mutualidade dos complexos, sejam estes políticos, artísticos, religiosos e etc., compreendendo a sua influência na totalidade do ser e da sociedade.

O trabalho é a categoria fundante do ser social, mas, não podemos desvalorizar ou superestimar a educação, pois é necessário compreender e entender a educação com práxis e não trabalho. Ela tem o poder de promover habilidades, conhecimento, comportamentos e etc., mas somente o trabalho é que impulsiona as transformações da sociedade, promovendo a sociabilidade e que esta é a diferença entre educação e trabalho. É o trabalho o ponto central e sua manifestação dependerá de cada momento histórico e social.

Saviani (2015), destaca que o ser humano necessita aprender a ser homem, precisa aprender a produzir sua própria existência. Portanto, o trabalho do homem é, ao mesmo tempo, a formação do homem, isto é, um processo educativo. A origem da educação coincide, então, com a origem do homem mesmo.

Ao contextualizar a educação, podemos compreender que essa relação vem desde homens primitivos, mas sofreu grandes interferências de acordo com as relações de trabalho, passando do modo de vida em comunidade para o modo de vida 
privado. Porém, por muitos séculos se manteve o regime de escravismo ao feudalismo, com as relações mantidas entre escravos e servos. Tonet (2013), reforça que o acúmulo de conhecimento sobre a natureza e a sociedade era precário, o que favorecia essa relação de imutabilidade e naturalidade.

Após o feudalismo, surgiu o sistema capitalista, o que fez convergir muitas ideias no processo de transição, pois essa mudança não ocorreu de forma brusca, mas sim, de forma transitória, com as explorações coloniais, surgimento do comércio e a organização do mesmo. Não é objeto de estudo deste artigo, compreender os sistemas capitalistas e feudalistas, mas, fazer a leitura de como a educação se passou nesses sistemas, e como elas foram direcionadas pelo trabalho e suas relações.

No sistema escravista e feudal, o conhecimento não era necessário aos escravos e servos, pois estes tinham a missão de fazer trabalhos grosseiros, repetitivos ou básicos, porém, um pequeno grupo de intelectuais detinha acesso ao conhecimento/educação. Diferentemente no modo privado capitalista, onde o trabalho se torna especializado e específico, necessitando de que as classes sociais, chamadas por este autor de populares, também sejam qualificadas. É nesse ambiente que se faz chegar nessas classes a educação, o conhecimento, porém de forma técnica, somente para atender o sistema capitalista. Tonet (2011), reforça que:

A sociedade deixou de ser uma comunidade, no sentido forte do termo, para converter-se em uma realidade social cindida, no seu interior, em grupos sociais antagônicos. A divisão social do trabalho separou os homens entre aqueles que produzem riqueza e aqueles que dela se apropriam privadamente. Daí, também, a separação entre trabalho manual e trabalho intelectual e o privilégio do segundo em relação ao primeiro.

Nesse momento em que o homem começa a ser explorado pelo homem, com o surgimento das classes sociais e a clara divisão do burguês e proletário, reorganização do trabalho e o domínio da vida humana, transformou radicalmente a vida e claro, a educação passou a ser direcionado pelos burgueses. Pois o trabalho é a origem do ser social, mas a manutenção do poder se dá pela educação. A burguesia atua para não abalar as estruturas sociais, pois é necessário garantir a produção e o lucro, e isso se dá pelo trabalho. Para este grupo, não é viável que a sociedade compreenda que ela é detentora da produção, que existe uma margem de lucro excessivo para a burguesia, o que continua distanciando ainda mais essas classes. Para Novaes (2018), afirma que:

Nesse sentido, a superação da alienação do trabalho em sua totalidade dificilmente virá através de um simples movimento econômico, como uma espécie de vírus que vai crescendo no interior do sociometabolismo do capital sem a mínima resistência do capital. Aqui, o papel da política é decisivo, no sentido de luta, dentro de um projeto revolucionário, num longo processo histórico de convencimento e construção na prática de uma sociedade controlada pelos seres humanos, autogovernada, que não seja comandada por uma força estranha: o capital.

Por fim, nota-se a relação do trabalho e educação, e o quanto uma depende ou não da outra. O trabalho é a categoria fundante da sociedade, e ele sempre direciona a educação de acordo com as transformações e necessidades sociais.

\section{Considerações Finais}

O trabalho é a categoria fundante do ser social, responsável pelo surgimento dos demais complexos sociais e da origem da sociabilidade humana. Nesse contexto, a educação é um complexo social que tem relação íntima com o trabalho, pois é a partir desse complexo, que a construção e o acúmulo do conhecimento permitem a criação de novos objetos, para amparar e garantir as relações sociais entre humanos e principalmente na relação de trabalho, inclusive no sistema capitalista.

O complexo social do trabalho tem sua importância diferenciada de acordo com as épocas, porém, essa importância foi medida de acordo com as relações do trabalho. No período comunitário, escravista e feudal, devido às formas de relações entre escravos e senhores, principalmente ao trabalho braçal, repetitivo e que não exigia tantas qualificações, o complexo 
social da educação não tinha tanta relevância. Ao surgir o sistema capitalista, esse complexo foi referenciado com maior importância, pois, o surgimento das produções e dos comércios, mudou a forma de vida dessas pessoas, exigindo uma sociedade com mais qualificação para atender ao sistema que se sustenta até os dias atuais.

Apesar de que a educação é um complexo de humanização, atualmente esse complexo não vem permitindo a formação de consciência da classe trabalhadora, que se permite a ser explorada no sistema atual, sem compreender que os bens produzidos a ela pertencem. Somente uma sociedade sem classes sociais é capaz de haver uma educação que garanta a emancipação e a consciência humana.

\section{Referências}

Almeida, R. A \& Almeida, I. F. (2021). Trabalho e aprendizagem: o direito às mediações. Rev. Ciência em movimento - Educação e direitos humanos. Edição 23(46).

Alves, D. J.. (2002). A filosofia no ensino médio: ambiguidades e contradições na LDB. Campinas, SP: Autores Associados, 2002.

Bizerra, F. A. (2015). Trabalho e ser social: uma relação genética. file:///C:/Users/Teste/Downloads/Eixo_1_198_2.pdf

Engels, F.(2021). O papel do trabalho na transformação do macaco em homem. Disponível em

http://www.marxists.org/portugues/marx/1876/mes/macaco.htm Acesso em 14 de setembro de 2021.

Fonte, S. S. D. (2018). Formação no e para o trabalho. Educação Profissional e Tecnológica em Revista, 2 (2), 6-19.

Gil, A. C. (2008). Métodos e técnicas de pesquisa social (6º ed). Ed. Atlas.

Jimenez, S. V \& Lima, M. F. (2011). O complexo da Educação em Luckács: uma análise à luz das categorias trabalho e reprodução social. Educação em Revista, 27 (2), 73-94.

Lukács, G. (1979). Ontologia do ser social: os princípios ontológicos fundamentais de Marx. São Paulo: Ciências Humanas, 1979.

Maceno, T. E. (2017). Educação e reprodução social: a perspectiva da crítica marxista. Ed. Instituto Luckács.

Marx, K. (1993) Manuscritos econômico-filosóficos (Tradução de Artur Morão, 1975, a partir de seleção de T. B. Bottomore. Prefácio de Erich Fromm). Lisboa: Edições 70 .

Nascimento, A. (2016). Trabalho e formação do espaço urbano. Ed. Coletivo Veredas.

Novaes, H. T. (2018). Trabalho emancipado e educação para além do capital na obra de István Mészáros. Rev. Trabalho emancipado e educação. 19(1), p.724.

Rolim, R. R.. (2018). Tendências históricas universais do ser social na ontologia de Lukács: apontamentos de uma leitura imanente. Rev. Direito e Práxis. 9 (3). Set 2018. <https://doi.org/10.1590/2179-8966/2017/27035 >

Santos, M. E. M. (2018). Relações históricas entre trabalho, educação e pobreza. Teresina-PI: EDUFPI, 2018.124 p.

Saviani, D. (2005). Pedagogia histórico-crítica: primeiras aproximações. 9. ed. rev. e ampl. Campinas: Autores Associados,

Tonet, I. (2012). Educação e ontologia marxiana. Revista HISTEDBR On-line, Campinas, SP, v. 11, n. 41e, p. 135-145, 2012. DOI: 10.20396/rho.v11i41e.8639900. Disponível em: https://periodicos.sbu.unicamp.br/ojs/index.php/histedbr/article/view/8639900. Acesso em: 23 maio.

Tonet, I. (2016). Método Científico: uma abordagem ontológica. Maceió: Coletivo Veredas, 